\title{
PENDUGAAN POTENSI KARBON JENIS-JENIS TANAMAN BERKAYU DI PEKARANGAN DESA TEGALWARU, KECAMATAN CIAMPEA, KABUPATEN BOGOR
}

\author{
Estimation of carbon potential in woody plant species in the yard of Tegal Waru Village, \\ Ciampea Sub-district, District Bogor
}

Nurheni Wijayanto $^{1^{*}}$ dan Maulana Musthofa Rasyiid Gunawan ${ }^{2}$

(Diterima Desember 2019/Disetujui Agustus 2020)

\begin{abstract}
Global warming is an environmental issue that related to the forestry. The strategy to reduce greenhouse gases emissions can be done by mitigation and adaptation. Agroforestry is one of excellent step for mitigation. One example of agroforestry form is home garden. Home garden is a system of land use which is located around the home. This research aims to estimate total carbon stock potential in all of kinds of woody plants in home garden at Tegalwaru Village, Ciampea, Bogor. This research use allometric method. The study was conducted in 30 home gardens of Tegalwaru Village selected by randomly. The results showed that there were 31 species of woody plants. Plants that dominate, namely: rambutans (Nephelium lappaceum), rose apple (Syzygium aqueum), mango (Mangifera indica), and jackfruit (Artocarpus heterophyllus). The total amount of biomass and carbon stocks for woody plants there is 14.98 ton ha-1 and 7.04 ton ha-1. Carbon stocks in woody plants at home garden of Tegalwaru Village is low carbon stocks.
\end{abstract}

Keywords: allometric, carbon potential, home garden, Tegalwaru Village, woody plants

\section{PENDAHULUAN}

Isu lingkungan yang terkait dengan kehutanan yang sampai saat ini masih marak dibahas adalah terjadinya pemanasan global. Emisi gas rumah kaca meningkat menyebabkan terjadinya pemanasan global (Manahan 2000). Menurut Hairiah dan Rahayu (2007) karbon dioksida $\left(\mathrm{CO}_{2}\right)$ merupakan salah satu komponen gas rumah kaca yang berperan sebagai perangkap panas di atmosfer, sehingga dapat menyebabkan terjadinya pemanasan global dan perubahan iklim Informasi mengenai kandungan karbon (C) diperlukan untuk merancang strategi menanggulangi pemanasan global.

Cara untuk mengurangi emisi gas rumah kaca adalah dengan adaptasi dan mitigasi. Adaptasi adalah upaya yang dilakukan untuk mengantisipasi dampak perubahan iklim yang sudah atau mungkin akan terjadi. Mitigasi adalah upaya untuk mengurangi emisi gas rumah kaca yang merupakan sumber penyebab terjadinya pemanasan global (Heriansyah 2005). Salah satu contoh mitigasi adalah agroforestri. Kontribusi agroforestri terhadap upaya mitigasi gas rumah kaca di udara cukup besar melalui banyaknya karbon yang tersimpan dalam sistem tersebut (Hairiah dan Rahayu 2007; Lestari dan Pramono 2014). Besarnya karbon yang tersimpan pada sistem agroforestri tidak bisa sebanyak hutan alam, namun masih jauh lebih banyak dari pada sistem pertanian monokultur. Hal yang terpenting adalah agroforestri

\footnotetext{
${ }^{1}$ Staf Pengajar Departemen Silvikultur, Fakultas Kehutanan dan Lingkungan Institut Pertanian Bogor

* Penulis korespondensi:

e-mail: nurheniw@gmail.com

${ }^{2}$ Mahasiswa Departemen Silvikultur, Fakultas Kehutanan Institut Pertanian Bogor
}

dapat memperkecil ancaman terjadinya alih fungsi lahan di masa yang akan datang.

Salah satu bentuk sistem agroforestri yang terdapat di masyarakat adalah pekarangan. Pekarangan merupakan suatu sistem penggunan lahan yang terletak sekitar tempat tinggal (Arifin 2010). Salah satu fungsi pekarangan yaitu terkait kegiatan penurunan emisi gas rumah kaca, yakni sebagai siklus karbon dan yang kedua sebagai penyimpan karbon (Arifin et al. 2009). Penelitian mengenai simpanan karbon pada sistem agroforestri khususnya pekarangan masih sedikit dilakukan, padahal dapat memberikan informasi dalam simpanan karbon dan upaya mitigasi pemanasan global. Oleh karena itu, perlu dilakukan penelitian pengukuran terhadap jumlah karbon yang tersimpan pada sistem agroforestri terutama pekarangan.

\section{METODE PENELITIAN}

\section{Waktu dan Tempat Penelitian}

Kegiatan penelitian dilakukan di Desa Tegalwaru, Kecamatan Ciampea, Kabupaten Bogor. Kegiatan pengambilan data dilaksanakan pada bulan Maret-April 2016. Kegiatan pengolahan data dilakukan pada bulan Juli-Agustus 2016.

\section{Alat dan Bahan}

Bahan utama yang digunakan dalam penelitian ini adalah tanaman berkayu mulai dari diameter di atas $5 \mathrm{~cm}$. Beberapa alat yang dipakai dalam penelitian antara lain peta, tally sheet, alat tulis, meteran jahit, walking stick, 
parang, dan tali raffia serta mengunakan perangkat lunak (software) Microsoft Excel.

\section{Metode Pelaksanaan}

\section{Penentuan sampel}

Pemilihan sampel memperhatikan kondisi rata-rata tanaman berkayu di pekarangan. Orientasi lapang secara lengkap dan pengumpulan data kepemilikan dan riwayat pengelolaan pekarangan kepada pemilik untuk menentukan sampel. Pengukuran pekarangan yang terpilih dilakukan secara acak dan tersebar pada 30 unit sampel pekarangan di Desa Tegalwaru. Masing-masing unit sampel diambil identitas pemilik (nama pemilik lahan, luas lahan, lokasi, dan jenis tanaman berkayu) (ARuPA 2014).

\section{Pengamatan di pekarangan}

Pengamatan dilakukan di pekarangan adalah pengumpulan data luas, pencatatan semua jenis tanaman berkayu, perhitungan jumlah tanaman berkayu di setiap petak ukur, pengukuran diameter tanaman berkayu, dan tinggi tanaman berkayu (Purwanto 2012).

\section{Metode pengumpulan data biomassa pohon}

Pengumpulan data dilakukan secara sensus terhadap semua jenis tanaman berkayu yang memiliki diameter $\geq$ $5 \mathrm{~cm}$. Data biomassa tegakan pohon yang diamati adalah diameter dan tinggi total. Data pendukung yang perlu dicatat adalah nomor pohon, nama jenis pohon, dan informasi lahan

\section{Analisis Data}

Perhitungan biomassa dan karbon pohon pada pekarangan

Tahapan analisis data dilakukan dengan cara mengetahui komposisi tanaman di pekarangan, menghitung biomassa tanaman berkayu, dan menghitung karbon tanaman berkayu. Komposisi jenis diketahui dengan menghitung kerapatan tanaman berkayu, frekuensi tanaman berkayu, dominasi, dan INP tingkat semai dan pancang serta tingkat pohon.

INP untuk semai dan pancang:

$$
\mathrm{INP}=\mathrm{KR}+\mathrm{FR}
$$

INP untuk tingkat pohon:

$$
\mathrm{INP}=\mathrm{KR}+\mathrm{FR}+\mathrm{DR}
$$

$$
\begin{array}{ll}
\text { Kerapatan } & =\frac{\text { Jumlah individu suatu jenis }}{\text { Luas petak contoh }} \text { (ind } / \text { ha) } \\
\text { Kerapatan Relatif } & =\frac{\text { Kerapatan suatu jenis }}{\text { Kerapatan seluruh jenis }} \times 100 \% \\
\text { Frekuensi } & =\frac{\text { Jumlah plot ditemukan suatu jenis }}{\text { Jumlah seluruh plot }} \\
\text { Frekuensi Relatif } & =\frac{\text { Frekuensi suatu jenis }}{\text { Frekuensi seluruh jenis }} \times 100 \%
\end{array}
$$

Dominansi

$$
=\frac{\text { Jumlah LBDS suatu jenis }}{\text { Luas petak contoh }}\left(\mathrm{m}^{2} / \mathrm{ha}\right)
$$$$
\text { Dominansi Relatif }=\frac{\text { Dominansi suatu jenis }}{\text { Dominansi seluruh jenis }} \times 100 \%
$$

(Indriyanto 2006).

Potensi biomassa tanaman berkayu yang ada pada pekarangan diduga menggunakan persamaan alometrik yang sudah ada sebelumnya. Apabila persamaan allometrik tidak ada maka mengunakan persamaan dari Katterings et al. (2001) dan untuk berat jensinya terdapat pada Tabel 1. Persamaanya sebagai berikut:

$$
Y=0.11 \times \rho \times D^{2+c}
$$

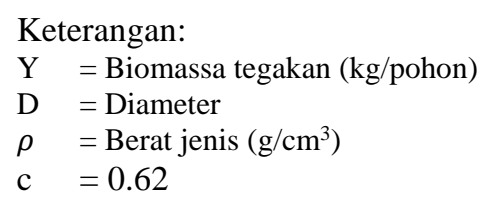

Namun, apabila mengunakan nilai volume maka harus dikonversi menjadi nilai biomassa pohon. Beberapa nilai konstanta untuk penghitungan biomassa dengan rumus alometrik yang sudah diketahui terdapat pada pada Tabel 2 (Balitbanghut 2013). Persamaan allometrik menggunakan persamaan sebagai berikut (Sutaryo 2009):

$$
Y=a \times D^{b}
$$

$$
\begin{aligned}
& \text { Keterangan: } \\
& \mathrm{Y} \quad=\text { Biomassa tegakan (kg/pohon) } \\
& \mathrm{D} \quad=\text { Diameter } \\
& \mathrm{a} \quad=\text { Konstanta } \mathrm{a} \\
& \mathrm{b} \quad=\text { Konstanta } \mathrm{b}
\end{aligned}
$$

Perhitungan karbon tegakan keseluruhan, menggunakan persamaan sebagai berikut (ARuPA 2014):

$$
\mathrm{C}_{\mathrm{s}}=0.4 \times \mathrm{Y}_{\mathrm{s}}
$$

Keterangan:

$$
\begin{array}{ll}
\mathrm{C}_{\mathrm{s}} & =\text { Karbon tanaman keseluruhan }\left(\mathrm{kg} \mathrm{ha}^{-1}\right) \\
\mathrm{Y}_{\mathrm{s}} & =\text { Biomassa tegakan tanaman keseluruhan } \\
& (\mathrm{kg} / \mathrm{pohon})
\end{array}
$$

Tabel 1 Berat jenis tanaman berkayu

\begin{tabular}{rlc}
\hline No & Nama Latin Jenis & $\mathrm{BJ}\left(\mathrm{g} \mathrm{cm}^{-3}\right)$ \\
\hline 1 & Mangifera indica & 0.64 \\
2 & Nephelium lappaceum & 0.91 \\
3 & Psidium guajava & 0.75 \\
4 & Leucaena glauca & 0.82 \\
5 & Manilkara kauki & 1.03 \\
6 & Plumeria rubra & 0.63 \\
7 & Averrhoa bilimbi & 0.52 \\
8 & Parkia speciosa & 0.45 \\
9 & Artocarpus heterophyllus & 0.61 \\
10 & Syzygium aqueum & 0.84 \\
11 & Annona muricata & 0.36 \\
12 & Durio zibethinus & 0.57 \\
13 & Lansium domesticum & 0.85 \\
14 & Ceiba pentandra & 0.47 \\
15 & Artocarpus altilis & 0.54 \\
16 & Samanea saman & 0.61 \\
\hline
\end{tabular}


Sementara, untuk menghitung jumlah total karbon tegakan keseluruhan menggunakan persamaan sebagai berikut (BSN 2011):

$$
\mathrm{C}_{\text {tots }}=\sum \mathrm{Y}_{\mathrm{s}}
$$

Keterangan

$$
\begin{array}{ll}
\mathrm{C}_{\text {tots }} & =\text { Karbon total tanaman keseluruhan }(\text { ton ha } \\
\mathrm{C}_{\mathrm{s}} & =\text { Karbon tanaman keseluruhan }\left(\mathrm{kg} \mathrm{ha}^{-1}\right)
\end{array}
$$

\section{Konversi data biomassa total}

Perhitungan konversi data biomassa total ke dalam ton/ha dapat menggunakan persamaan yang sudah dikembangkan oleh ARuPA (2014). Persamaan yang dipakai sebagai berikut:

$$
\begin{gathered}
\text { Total Biomassa pada seluruh plot }(\text { ton })=\frac{\text { Total biomassa }}{1000 \mathrm{~kg}} \\
\text { Total biomassa per plot }=\frac{\text { Total biomassa }(\text { ton })}{\text { Jumlah Plot }}
\end{gathered}
$$

Total biomassa $($ ha $)=$ Biomassa $($ per plot $) \times \frac{10.000 \mathrm{~m}}{\text { Ukuran Plot }}$

\section{HASIL DAN PEMBAHASAN}

\section{Kondisi Umum Desa Tegalwaru}

Desa Tegalwaru terletak pada $106^{\circ} 42^{\prime} 04.3^{\prime \prime}$ 10641'26.9" Bujur Timur dan 6³3'53.3" - 6³4'39.4" Lintang Selatan. Desa Tegalwaru secara administrasi terletak di Kecamatan Ciampea Kabupaten Bogor. Desa Tegalwaru berbatasan dengan desa lainnya. Batas sebelah utara berbatasan dengan Desa Bojong Jengkol. Batas selatan berbatasan dengan Desa Cinangka. Batas

Tabel 2 Konstanta pohon

\begin{tabular}{lll}
\hline Jenis & $\mathrm{a}$ & $\mathrm{b}$ \\
\hline Schima wallichi $i$ & 0.4590 & 1.3640 \\
Acacia mangium & 0.1990 & 2.1480 \\
Dalbergia latifolia & 0.7458 & 0.6394 \\
Eucalyptus grandis & 0.0678 & 2.5794 \\
Gmelina arborea & 0.0600 & 0.8800 \\
Pinus Merkusii & 0.0936 & 2.4323 \\
Shorea laprosula & 0.0320 & 2.7808 \\
Switenia Mahagoni & 0.9030 & 0.6840 \\
Tectona grandis & 0.0540 & 2.5790 \\
\hline
\end{tabular}

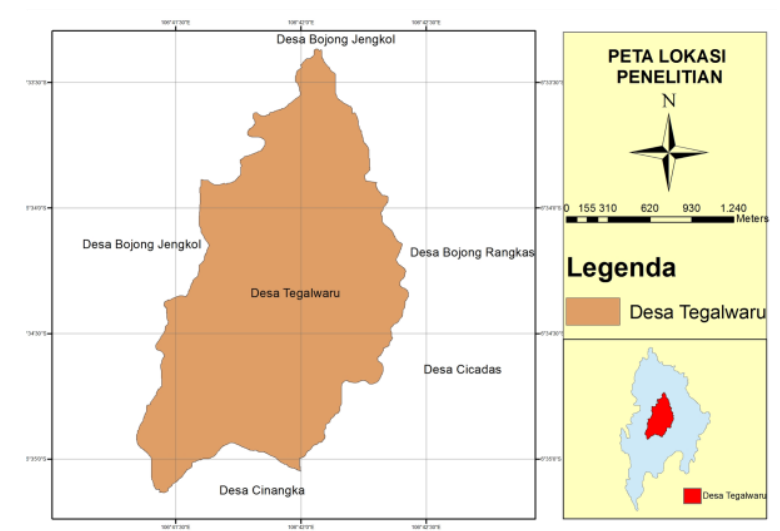

Gambar 1 Peta Desa Tegalwaru barat berbatasan dengan Desa Bojong Rangkas dan Desa Cicadas. Batas timur berbatasan dengan Desa Bojong Jengkol. Peta Desa Tegalwaru terdapat pada Gambar 1. Desa Tegalwaru mempunyai penduduk sejumlah 13254 jiwa yang terbagi dalam tiga dusun. Desa Tegalwaru terdiri dari tiga dusun, yaitu: Dusun Tegalwaru, Dusun Cikarawang, Dusun Ciampea Hilir (Desa Tegalwaru 2015).

Desa Tegalwaru berada dalam ketinggian 200 - 500 mdpl. Keadaan topografinya berbukit-bukit kecil. Suhu di Desa Tegalwaru berkisar antara 25 - $35{ }^{\circ} \mathrm{C}$. Desa Tegalwaru memiliki tanah yang subur, kondisi tersebut dimanfaatkan oleh penduduk. Penduduk sebagian besar berprofesi pada bidang pertanian. Peruntukan lahan juga sebagian besar untuk pertanian. Sekitar 220 ha dipergunakan untuk persawahan. Luas lahan yang digunakan untuk pemukiman seluas 80.5 ha (Desa Tegalwaru 2015). Pekarangan berada dalam luasan tanah yang dijadikan pemukiman, karena pekarangan merupakan merupakan taman rumah, halaman rumah, dan ruang terbuka di sekeliling rumah.

Pekarangan menurut Sopiah (2006) dan Galhena et al. (2013) pada umumnya ditanami oleh tanaman hortikultur, tanaman kehutanan, tanaman perkebunan, tanaman pagar tanaman hias, tanaman berkhasiat obat, dan tanaman sayur-sayuran. Pernyataan tersebut sesuai kondisi pekarangan yang berada di Desa Tegalwaru. Tanaman yang terdapat di pekarangan juga dikombinasikan dengan ternak, seperti ayam, bebek, sapi, dan kambing milik penduduk. Penduduk memiliki pekarangan pada umumnya untuk menjaga suasana rumah agar asri, tempat bersosialisasi dengan warga lain, dan mendapatkan hasil pangan dari tanaman. Hal tersebut sesuai dengan fungsi pekarangan menurut Sopiah (2006) dan Arifin et al. (2009).

Pekarangan di Desa Tegalwaru memiliki berbagai luasan. Berdasarkan Peraturan Menteri Pekerjaan Umum No. 5 tahun 2008 pekarangan kecil merupakan pekarangan yang luasnya kurang dari $200 \mathrm{~m}^{2}$, pekarangan sedang memiliki luas antara $200 \mathrm{~m}^{2}$ hingga $500 \mathrm{~m}^{2}$, pekarangan besar memiliki luas lebih dari 500 $\mathrm{m}^{2}$.

\section{Jenis-Jenis Tanaman Berkayu Di Pekarangan}

Penelitian ini dilakukan di 30 pekarangan milik penduduk Desa Tegalwaru. Pekarangan dipilih dari berbagai luasan pekarangan mulai dari $45 \mathrm{~m}^{2}$ sampai 8 $000 \mathrm{~m}^{2}$. Hasil dari pengamatan terdapat pada Tabel 3 .

Pola penanaman pada pekarangan tersebut sebagian besar secara menyebar, namun ada juga yang secara mengelompok. Pada Tabel 4 diketahui bahwa terdapat 31 jenis tanaman berkayu. Jenis-jenis tanaman berkayu yang terdapat di pekarangan Desa Tegalwaru disajikan pada Tabel 4. Jenis tanaman yang paling dominan di pekarangan Desa Tegalwaru diketahui dengan menghitung nilai INP suatu jenis (Indriyanto 2006).

Pemilihan jenis tanaman pada pekarangan Desa Tegalwaru sesuai dengan pernyataan Irwan (2015), yaitu dipengaruhi oleh tingkat kesukaan dari pemilik lahan, nilai ekonomi, serta kemudahan mendapatkan bibit. Jenis tanaman kehutanan seperti jati dan gmelina yang tumbuh di lahan pekarangan relatif sedikit. Hal itu karena jenis tanaman kehutanan sebagian besar ditanam dan tumbuh 
di hutan rakyat Desa Tegalwaru. Pekarangan di Desa Tegalwaru sebagian besar hanya berada di depan rumah. Menurut Arifin et al. (2009) pekarangan yang berada di halaman depan pada umumnya merupakan lahan untuk menanam tanaman hias dan tanaman buah.

\section{Kandungan Biomassa Dan Karbon Di Pekarangan Desa Tegalwaru}

Tabel 4 merupakan hasil analisis data hasil inventarisasi pekarangan di Desa Tegalwaru dari 30 responden. Hasil yang diperoleh adalah rekapitulasi jumlah pohon, biomassa per hektar dan karbon per hektar untuk masing-masing jenis.

Jumlah total biomassa pada pekarangan Desa Tegalwaru sebesar 14.98 ton $\mathrm{ha}^{-1}$. Jumlah total biomassa per jenis terdapat pada Tabel 4.

Karbon merupakan salah satu unsur yang terkandung dalam biomassa. Karbon ditaksir sekitar 0.47 dari kandungan biomassa pada suatu tanaman (BSN 2011). Penelitian ini didapatkan hasil jumlah total simpanan karbon tanaman berkayu di pekarangan Desa Tegalwaru sebesar 7.04 ton $\mathrm{ha}^{-1}$.

Bappenas (2010) membagi 3 kriteria simpanan karbon. Stok karbon tinggi (> 100 ton $\mathrm{C} \mathrm{ha}^{-1}$ ), stok karbon sedang $\left(35-100\right.$ ton $\left.\mathrm{C}^{-1}\right)$, dan stok karbon rendah $\left(<35\right.$ ton $\left.\mathrm{C} \mathrm{ha}^{-1}\right)$.

Stok karbon tanaman berkayu di pekarangan Desa Tegalwaru termasuk dalam kategori stok karbon rendah. Nilai simpanan karbon yang rendah ini cukup wajar karena simpanan karbon yang dihitung dalam penelitian masih belum lengkap. Komponen biomassa yang dihitung hanya dari bagian atas permukaan tanah yaitu tanaman berkayu ukuran diameter batang $\geq 5 \mathrm{~cm}$, dan berfokus tanaman yang masih hidup. Sementara menurut Balitbanghut (2010) menjelaskan bahwa 5 sumber karbon yang harus diukur di dalam ekosistem hutan, yaitu 1) biomassa di atas tanah (above ground biomass), 2) biomassa di bawah tanah (below ground biomass), 3) pohon yang mati (dead wood), 4) serasah (litter), dan 5) tanah (soil).

Tabel 3 Hasil inventarisasi jenis tanaman berkayu di pekarangan

\begin{tabular}{|c|c|c|c|c|}
\hline No & $\begin{array}{c}\text { Pola } \\
\text { penanaman }\end{array}$ & $\begin{array}{c}\text { Luas lahan } \\
\left(\mathrm{m}^{2}\right)\end{array}$ & Jenis tanaman & $\begin{array}{c}\text { Jumlah pohon } \\
\text { (individu) }\end{array}$ \\
\hline 1 & Menyebar & 163 & Mangga, coklat, rambutan & 4 \\
\hline 2 & Menyebar & 1460 & Mangga, jambu biji, rambutan, petai cina, sawo & 16 \\
\hline 3 & Menyebar & 120 & Rambutan & 3 \\
\hline 4 & Menyebar & 150 & Jambu biji, bunga kamboja, belimbing & 6 \\
\hline 5 & Menyebar & 370 & Jeruk, nangka, petai, namnam, belimbing, rambutan, melinjo & 11 \\
\hline 6 & Menyebar & 100 & Jambu air, jambu biji, mengkudu & 4 \\
\hline 7 & Menyebar & 200 & Mangga, kelengkeng & 3 \\
\hline 8 & Menyebar & 225 & Mangga, rambutan & 4 \\
\hline 9 & Menyebar & 120 & Jambu monyet, jeruk bali, & 3 \\
\hline 10 & Menyebar & 150 & Jambu air, nangka, belimbing, mangga, rambutan & 8 \\
\hline 11 & Menyebar & 200 & Rambutan & 2 \\
\hline 12 & Menyebar & 100 & Jeruk, rambutan, jambu biji, jambu monyet, jambu air, sirsak & 7 \\
\hline 13 & Menyebar & 300 & Jambu air & 2 \\
\hline 14 & Menyebar & 100 & Mangga, nangka & 2 \\
\hline 15 & Mengelompok & 240 & Rambutan, nangka & 11 \\
\hline 16 & Menyebar & 600 & Rambutan, mangga & 3 \\
\hline 17 & Menyebar & 720 & Belimbing, jambu biji, rambutan, gmelina, petai cina & 9 \\
\hline 18 & Menyebar & 420 & Rambutan, nangka & 3 \\
\hline 19 & Menyebar & 400 & Nangka & 1 \\
\hline 20 & Menyebar & 45 & Mangga & 1 \\
\hline 21 & Menyebar & 400 & Pala, rambutan & 3 \\
\hline 22 & Menyebar & 250 & Jambu air, jambu biji & 3 \\
\hline 23 & Menyebar & 250 & Durian, jambu biji & 2 \\
\hline 24 & Menyebar & 450 & Jambu biji, mangga, nangka, rambutan & 5 \\
\hline 25 & Menyebar & 210 & Jambu biji, duku & 3 \\
\hline 26 & Menyebar & 150 & Rambutan, durian, nangka, jati & 11 \\
\hline 27 & Menyebar & 8000 & $\begin{array}{l}\text { Mengkudu, sirsak, kelor, sukun, trembesi, alpokat, kapuk, } \\
\text { belimbing }\end{array}$ & 15 \\
\hline 28 & Menyebar & 100 & Kersen, petai cina & 4 \\
\hline 29 & Menyebar & 100 & Jeruk, jambu air, mangga & 9 \\
\hline 30 & Menyebar & 2500 & Kamboja, sawo duren, jambu air, mangga & 21 \\
\hline
\end{tabular}




\section{SIMPULAN DAN SARAN}

\section{Simpulan}

Pekarangan di Desa Tegalwaru terdiri dari 31 jenis tanaman berkayu. Jenis tanaman yang mendominasi adalah tanaman rambutan, tanaman mangga, dan tanaman nangka. Tanaman berkayu yang memiliki diameter $\geq 5 \mathrm{~cm}$ di pekarangan Desa Tegalwaru memiliki jumlah total biomassa sebesar 14.98 ton $\mathrm{C} \mathrm{ha}^{-1}$. Jumlah total kandungan karbon pada tanaman berkayu yang memiliki diameter $\geq 5 \mathrm{~cm}$ di pekarangan Desa Tegalwaru sebesar 7.04 ton $\mathrm{C}$ ha $^{-1}$. Jumlah total simpanan karbon sebesar 7.04 ton $\mathrm{C} \mathrm{ha}^{-1}$ tergolong stok karbon rendah.

\section{Saran}

Penelitian lebih lanjut perlu dilakukan tentang perhitungan simpanan karbon di sumber karbon lainnya, yaitu di bagian tumbuhan bawah, pohon yang mati, serasah, dan tanah. Penelitian itu perlu dilakukan agar hasil yang didapatkan lebih lengkap.

\section{DAFTAR PUSTAKA}

Arifin HS. 2010. Kearifan Lokal dalam Sistem Agroforestri Tradisional di Pekarangan Untuk Mendukung Konservasi Agrobiodiversity dan Ketahanan Pangan Keluarga. Di dalam: Budiadi, Wulandari C, Wijayanto N, editor. Prosiding Agroforestri Tradisional di Indonesia; 2010

Tabel 4 Hasil analisis data inventarisasi semua jenis tanaman berkayu

\begin{tabular}{|c|c|c|c|c|c|c|}
\hline No & Jenis tanaman & Nama Latin & $\begin{array}{c}\text { Jumlah } \\
\text { tanaman } \\
\text { (individu) }\end{array}$ & INP $(\%)$ & $\begin{array}{l}\text { Biomassa per } \\
\text { ha (ton ha }{ }^{-1} \text { ) }\end{array}$ & $\begin{array}{l}\text { Karbon per ha } \\
\quad(\text { ton ha } \\
-1)\end{array}$ \\
\hline 1 & Mangga & Mangifera indica & 19 & 38.34 & 2.71638 & 1.276701 \\
\hline 2 & Cokelat & Theobroma cacao. & 1 & 1.63 & 0.00187 & 0.000876 \\
\hline 3 & Rambutan & Nephelium appaceum & 35 & 59.97 & 5.57373 & 2.619651 \\
\hline 4 & Jambu biji & Psidium guajava & 16 & 22.48 & 0.53293 & 0.250475 \\
\hline 5 & petai cina & Leucaena glauca & 4 & 6.91 & 0.23987 & 0.112739 \\
\hline 6 & Sawo & Manilkara kauki & 1 & 1.67 & 0.01055 & 0.004958 \\
\hline 7 & Bunga kamboja & Plumeria rubra & 6 & 5.84 & 0.02888 & 0.013575 \\
\hline 8 & Petai & Parkia speciose & 1 & 2.40 & 0.07724 & 0.036305 \\
\hline 9 & Jeruk & Citrus aurantium & 9 & 10.52 & 0.12988 & 0.061044 \\
\hline 10 & Nangka & Artocarpus heterophyllus & 19 & 35.67 & 2.60437 & 1.224222 \\
\hline 11 & Namnam & Cynometra cauliflora & 2 & 2.23 & 0.00188 & 0.000844 \\
\hline 12 & Melinjo & Gnetum gnemon & 1 & 1.71 & 0.00347 & 0.001631 \\
\hline 13 & Jambu air & Syzygium aqueum & 21 & 26.60 & 1.20833 & 0.568152 \\
\hline 14 & Mengkudu & Morinda citrifolia & 2 & 4.20 & 0.04939 & 0.023214 \\
\hline 15 & Kelengkeng & Dimocarpus longan & 2 & 2.31 & 0.00595 & 0.002796 \\
\hline 16 & Jambu monyet & Anacardium occidentale & 3 & 4.69 & 0.03751 & 0.017629 \\
\hline 17 & Jeruk bali & Citrus maxima & 1 & 2.03 & 0.01652 & 0.007764 \\
\hline 18 & Gmelina & Gmelina arborea & 3 & 5.72 & 0.00001 & 0.000003 \\
\hline 19 & Sirsak & Annona muricata & 2 & 3.65 & 0.02736 & 0.012858 \\
\hline 20 & Pala & Myristica fragrans & 2 & 5.78 & 0.28890 & 0.135782 \\
\hline 21 & Durian & Durio zibethinus & 2 & 4.77 & 0.19170 & 0.090099 \\
\hline 22 & Jati & Tectona grandis & 2 & 2.29 & 0.02573 & 0.012093 \\
\hline 23 & Duku & Lansium domesticum & 1 & 3.51 & 0.44936 & 0.211198 \\
\hline 24 & Kelor & Moringa oleifera & 3 & 4.34 & 0.06119 & 0.028761 \\
\hline 25 & Sukun & Artocarpus altilis & 1 & 2.09 & 0.05090 & 0.023923 \\
\hline 26 & Trembesi & Samanea saman & 6 & 6.99 & 0.27415 & 0.128850 \\
\hline 27 & Kapuk & Ceiba pentandra & 1 & 2.27 & 0.06509 & 0.030590 \\
\hline 28 & Kersen & Muntingia calabura & 2 & 2.32 & 0.00620 & 0.002914 \\
\hline 29 & Sawo duren & Chrysophyllum cainito & 3 & 3.26 & 0.02811 & 0.013213 \\
\hline 30 & Belimbing & Averrhoa bilimbi & 7 & 11.48 & 0.24429 & 0.114816 \\
\hline \multirow[t]{3}{*}{31} & Alpukat & Persea americana & 1 & 12.35 & 0.02644 & 0.012425 \\
\hline & Total & & 179 & 300.00 & 14.98 & 7.04 \\
\hline & Rata-Rata & & & & 0.48 & 0.23 \\
\hline
\end{tabular}


Desember; Lampung, Indonesia. Lampung (ID): Universitas Lampung. hlm. 35-49.

Arifin HS, Munandar A, Arifin NHS dan Kaswanto. 2009. Pemanfaatan Pekarangan di Pedesaaan. Bogor (ID): Biro Perencanaan Sekjen Deptan bekerjasama dengan Departemen Arsitektur Lanskap, Faperta IPB. Bahan penyuluhan

[ARuPA] Aliansi Relawan Untuk Penyelamatan Alam. 2014. Proyeksi Cadangan Karbon di Hutan Rakyat Desa Terong, Kecamatan Dlingo, Kabupaten Bantul. Yogyakarta (ID): Biro Penerbit ARuPA.

[Balitbanghut] Badan Penelitian dan Pengembangan Kehutanan. 2013. Pedoman Penggunaan Model Alometrik Untuk Pendugaan Biomassa dan Stok Karbon Hutan di Indonesia. Bogor (ID): Pusat Penelitian dan Pengembangan Konservasi dan Rehabilitasi, Badan Penelitian dan Pengembangan Kehutanan.

[Balitbanghut] Badan Penelitian dan Pengembangan Kehutanan. 2010. Pedoman Pengukuran Karbon untuk Mendukung Penerapan REDD+ di Indonesia. Bogor (ID): Pusat Penelitian dan Pengembangan Perubahan Iklim dan Kebijakan, Badan Penelitian dan Pengembangan Kehutanan.

[Bappenas] Badan Perencanaan Pembangunan Nasional. 2010. Strategi nasional REDD+. Jakarta (ID). Bappenas-Kemenhut-UN-REDD Programme Indonesia.

[BSN] Badan Standarisasi Nasional. 2011. Pengukuran dan Perhitungan Cadangan Karbon-Pengukuran Lapangan untuk Penaksiran Cadangan karbon Hutan (ground based forest carbon accounting). Jakarta (ID): BSN

Galhena DH, Freed R, Maredia KM. 2013. Home gardens: a promising approach to enhance household food security and wellbeing. Agriculture and Food Security 2013. 2(8). Hal 213. doi: 10.1186/2048-7010-2-8.

Hairiah K dan Rahayu S .2007. Pengukuran Karbon Tersimpan Di Berbagai Macam Penggunaan Lahan. Bogor (ID): World Agroforestry Centre (ICRAF) Bogor.

Heriansyah I. 2005. Potensi hutan tanaman indsutri dalam mensequester karbon: studi kasus di hutan tanaman akasia dan pinus. Inovasi Online, Vol.3/XVII/Maret 2005. PPI Jepang.

Indriyanto. 2006. Ekologi Hutan. Jakarta (ID): Bumi Aksara

Irwan SNR dan Sarwadi A. 2015. Lanskap Pekarangan Produktif Di Permukiman Perkotaan dalam
Mewujudkan Lingkungan Binaan Berkelanjutan. Di dalam : [Editor tidak diketahui]. Prosiding Seminar Nasional Sains dan Teknologi; 2015 Nov 17; Jakarta, Indonesia. Jakarta (ID): Fakultas Teknik Universitas Muhammadiyah Jakarta. Hlm 1-11; [diunduh pada 2016 Agustus 18]. Tersedia pada

htttp;//www.jurnal.ftumj.ac.id/index.php/semnast ek

Lestari S dan Pramono BT. 2014. Penguatan Agroforestri Dalam Upaya Mitigasi Perubahan Iklim: Kasus Kabupaten Bengkulu Tengah Provinsi Bengkulu. Jurnal Penelitian Sosial dan Ekonomi Kehutanan. 11(1) :1-12.doi: 10.20886/jsek.2014.11.1.1-12

[Kementerian Pekerjaan Umum] Departemen Pekerjaan Umum. 2008. Peraturan Menteri Pekerjaan Umum Republik Indonesia Nomor: P.05/PRT/M/2008 tentang Pedoman Penyediaan dan Pemanfaatan Ruang Terbuka Hijau di Kawasan Perkotaan.Jakarta(ID): Kementerian Pekerjaan Umum.

Ketterings QM, Coe R, Van Noordwijk M, Ambagau Y, Palm CA. 2001. Reducing Uncertainty in The Use of Allometric Biomass Equations for Predicting Above-Ground Tree Biomass in Mixed Secondary Forests. For. Ecol. \& Manage 146: 199-209

Manahan ES. 2000. Environmental Chemistry. Boca Raton (US). Lewis Publishers.

Purwanto RH, Rohman, Maryudi A, Yuwono T, Permadi DB, Sanjaya M. 2012. Potensi Biomassa Dan Simpanan Karbon Jenis-Jenis Tanaman Berkayu Di Hutan Rakyat Desa Nglanggeran, Gunungkidul, Daerah Istimewa Yogyakarta. Jurnal Ilmu Kehutanan. 6(2):128-141

Seng OD. 1990. Berat Jenis dari Jenis-Jenis Kayu Indonesia dan Pengertian Beratnya Kayu untuk Keperluan Praktek. Soewarsono PH, penerjemah. Bogor (ID): Pusat Penelitian dan Pengembangan Hasil Hutan. Terjemahan dari: Specific Gravity of Indonesian Woods and its Significance for Practical Use.

Sopiah P. 2006. Menghijaukan Pekarangan Dengan Tanaman yang Bermanfaat. Jakarta (ID): PT Sinergi Pustaka.

Sutaryo D. 2009. Penghitungan Biomassa Sebuah Pengantar untuk Studi Karbon dan Perdagangan Karbon. Bogor (ID). Wetlands International Indonesia Programme. 